\title{
Jobs are not just about how much money
}

Last update: 31 January 2020

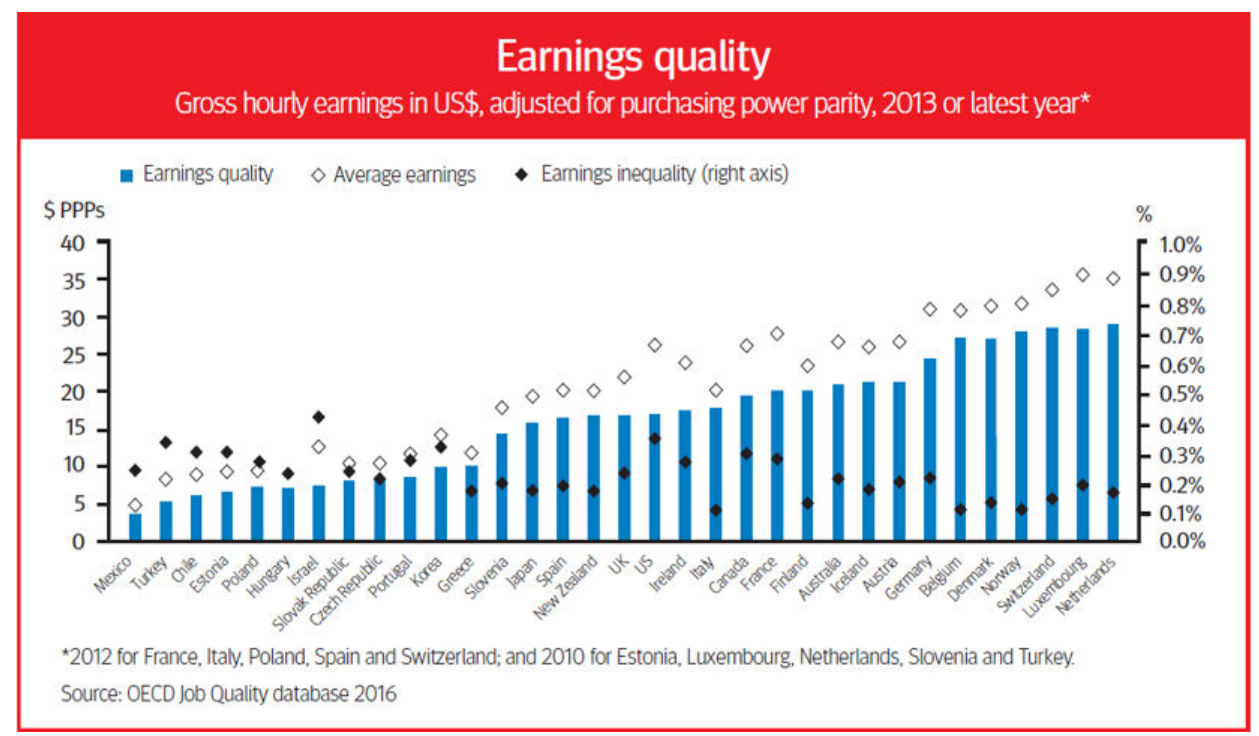

When it comes to jobs and earnings, quality counts, too. Indeed, as has been argued before in these pages, good pay, labour market security and a decent working environment can go hand in hand with high employment. New OECD data on the quality of jobs in 45 countries support this view. The data focus on the outcomes for workers in three broad areas connected with well-being: first, earnings quality, which considers employment's contribution to material living conditions and earnings distribution among the workforce; second, labour market security, which looks at the risks and costs of becoming unemployed; and third, the quality of the working environment.

The database puts overall job quality as highest in Australia, Austria, Denmark, Finland, Germany, Luxemburg, Norway, and Switzerland-countries that perform relatively well on at least two of the three dimensions of job quality-and lowest in Estonia, Greece, Hungary, Italy, Poland, Portugal, the Slovak Republic, Spain and Turkey. For earnings quality (our chart), the best performances come from the Netherlands, Luxembourg and Switzerland, and lowest in Mexico, Turkey and Chile, with countries such as Italy, Japan and the US hovering in the middle. The data also show that young workers and the unskilled face lower earnings and more insecurity and job strain than other groups. Women suffer from substantially lower employment rates than men and face a wide pay gap, but are less likely than men to experience job strain. 
COECD Observer No 305 Q1 2016

More data and insights on job quality

See also "More and better jobs for an inclusive recovery" by Martine Durand and Stefano Scarpetta in OECD Yearbook 2015. 